\title{
Dynamic Splitting Behavior and the Constitutive Relationship of Frozen Sandstone Containing a Single Fissure
}

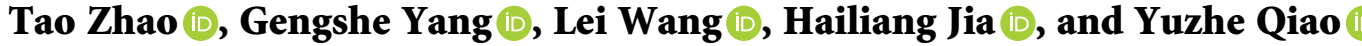 \\ College of Architecture and Civil Engineering, Xi'an University of Science and Technology, 58 Yanta Middle Road, Xi'an, \\ Shaanxi Province, China \\ Correspondence should be addressed to Hailiang Jia; hailiang.jia@xust.edu.cn
}

Received 3 December 2020; Revised 8 March 2021; Accepted 16 April 2021; Published 22 April 2021

Academic Editor: Bangbiao Wu

Copyright (c) 2021 Tao Zhao et al. This is an open access article distributed under the Creative Commons Attribution License, which permits unrestricted use, distribution, and reproduction in any medium, provided the original work is properly cited.

Fractured sandstone is widely distributed in mining areas throughout western China where the artificial freezing method is extensively adopted to construct vertical shafts. Blasting and excavation generate stress waves and break frozen fractured sandstone. Among the failure modes of frozen fractured rocks, tensile failure is very common. In this study, the dynamic tensile strength of fractured sandstone samples with four crack inclination angles $\left(0^{\circ}, 30^{\circ}, 60^{\circ}\right.$, and $\left.90^{\circ}\right)$ is tested by using a split Hopkinson pressure bar at four subzero temperatures $\left(-5,-10,-15\right.$, and $\left.-20^{\circ} \mathrm{C}\right)$. Accordingly, a damage constitutive relationship that considers the effect of fissure angle and freezing temperature is established. The results show the following: (1) the fissure angle does not significantly affect the dynamic tensile strength of frozen fractured sandstone but mainly affects the failure mode of the sample. (2) The dynamic tensile strength of fractured sandstone has a negative linear correlation with the freezing temperature. (3) When the fissure angle is small, only tensile cracking occurs; when the fissure angle is large, tensile cracking occurs along both the loading direction and the fissure; and shear cracking occurs along the fissure as well. (4) Regardless of the fissure angle, tensile cracking is initiated at the stress-concentration zone and then propagates towards the loading end. Fissure ice provides both resistance to deformation and resistance to crack propagation which affects the crack propagation and coalescence mode. A dynamic constitutive relationship is established by considering the effects of fissure angle and freezing temperature on the dynamic properties of frozen fractured sandstone, which is proven to be highly reliable and provides a reference and basis to study the dynamic mechanical properties of similar rock types.

\section{Introduction}

A large number of mine shafts in western China pass through Cretaceous strata. These strata have a short sedimentation time, containing many macro- and mesoscale fissures, and are in a water-rich state $[1,2]$. The artificial freezing method has become the best plan for vertical shaft construction in water-rich soft rock strata $[3,4]$. The fractured rock mass is easily damaged in blasting and excavation by the action of stress waves [5,6]. Due to the complex characteristics of rock mass structure, the dynamic mechanical behavior of frozen rock mass and the underlying mechanisms of crack propagation induced by impact loading are unclear [7].

Dynamic mechanical properties of fractured rock at room temperature have been investigated vastly primarily through the split Hopkinson pressure bar test device [8, 9], which can determine the dynamic compressive strength [10], dynamic tensile strength [11], dynamic fracture toughness [12], and other mechanical properties of the material [13, 14]. Dong et al. [15] used a separate Hopkinson pressure bar system to study the fracture behaviors of rock plates containing a single fissure and an ultra-high-speed camera system combined with the digital image correlation (DIC) method was adopted to record the transient fracture process. Li [16] used an improved Hopkinson pressure bar device to test the dynamic mechanical properties of prismatic marble with a single defect, and the effects of different crack angles and lengths on the dynamic mechanical properties were analyzed. Yan [17] conducted a dynamic compression test on rock specimens with multiple parallel cracks; the effects of the strain rate and crack strength on the 
dynamic response of the fractured specimen strength, deformability, progressive failure behavior, rock fragmentation characteristics, and energy dissipation were considered. Li [18] performed numerical simulations on the dynamic mixed mode I/II fracture behavior of fractured rock employing notched semicircular bending (NSCB) models.

A number of studies have been conducted on frozen intact rocks. Yang et al. [19] considered Cretaceous red sandstone and conducted the SHPB dynamic impact test to study its deformation, failure, and energy transfer laws under low-temperature conditions. The dynamic mechanical properties of weakly consolidated soft rock under different freezing temperatures were studied using the split Hopkinson pressure bar system, and a dynamic constitutive model considering the temperature effects was established $[20,21]$. Weng et al. [22] studied the effects of strain rate on the dynamic mechanical properties of dry siltstone and saturated siltstone at low temperatures, and the associated mechanism of water/ice weakening and strengthening of the dynamic mechanical properties of siltstone was discussed. Shan et al. [23] studied the effect of strain rates on the damage distribution and broken shape of frozen red sandstone subjected to dynamic compression. The above studies reveal primary principles of the dynamic mechanical properties of frozen rocks and form the basis for understanding the dynamic mechanical properties of the frozen rock mass. However, the scarcity of systematic studies on the dynamic mechanical properties poses risk to blasting excavation of frozen rock mass.

In this study, the SHPB system was used to perform dynamic splitting tests on sandstone samples containing a single artificial fissure filled with ice at different freezing temperatures $\left(-5,-10,-15,-20{ }^{\circ} \mathrm{C}\right)$ and with loading angles $\left(0^{\circ}, 30^{\circ}, 60^{\circ}\right.$, and $\left.90^{\circ}\right)$. The reason for adopting samples containing a single fissure is that it will make it easier to acquire the first-order rules of how predominant factors (e.g., loading angle and freezing temperature) affect the dynamic properties of frozen fractured rock. The dynamic mechanical properties and failure process of the sandstone samples were studies along with the associated morphological analysis. The crack propagation process was recorded using high-speed photography equipment. A dynamic constitutive relationship is established by considering the effects of initial multiscale damage and freezing temperature on the dynamic properties of frozen fractured sandstone.

\section{Methodology}

2.1. Specimen Preparation. The rock used in this study was medium-coarse-grained yellow sandstone commonly found in the mining areas of western China. An entire rock block with good uniformity was selected as the specimen. A core drill was used to extract a cylindrical specimen with a diameter of $50 \mathrm{~mm}$. According to the standards of the International Society of Rock Mechanics, the height of the specimen was $25 \mathrm{~mm}$. The artificial crack was cut across the center of a sample through a water jet scalpel; its length was 20-22 mm with an opening of $1-1.7 \mathrm{~mm}$ (Figure $1(\mathrm{a})$ ). The basic physical and mechanical parameters of the sandstone at $20{ }^{\circ} \mathrm{C}$ are shown in Table 1.

The sample with good integrity was selected as the test to ensure that the sample is in full contact with the end surface of the rod during loading based on the requirements of the dynamic splitting test. This test involves four freezing temperatures $\left(-5,-10,-15\right.$, and $\left.-20^{\circ} \mathrm{C}\right)$ and four loading angles $\left(0^{\circ}, 30^{\circ}, 60^{\circ}\right.$, and $\left.90^{\circ}\right)$. Fissure angle, labeled by $\theta$, is defined as the angle between the loading direction and the artificial fissure. Considering the influence of material inhomogeneity on the dispersion of the test results, three specimens are carried out under the same test conditions with the test average selected for the analysis of the results. Therefore, a total of 48 fractured sandstone specimens were used in this test.

Heat treatment was conducted on specimens so that their dry mass was obtained; combining with their saturation mass, the porosity of these samples can be calculated. We used porosity as an index for selecting samples with similar values.

Before the dynamic split test, specimens were conditioned as follows: The specimen was placed in the oven for $24 \mathrm{~h}$ at a temperature of $105^{\circ} \mathrm{C}$ before drying in a vacuum saturation instrument; the gauge pressure was at $-0.1 \mathrm{MPa}$ and maintained for $2 \mathrm{~h}$, and then, the specimen was placed in distilled water to continue pumping. After $3 \mathrm{~h}$ under vacuum, the rock specimen was placed in distilled water for $48 \mathrm{~h}$. Afterwards, the artificial fissure was sealed with a thin layer of Vaseline at both sides; then, water was injected into it. The specimens were finally wrapped with plastic film and placed into an environmental chamber to freeze at testing temperatures for at least $24 \mathrm{~h}$ (Figure $1(\mathrm{~b})$ ).

2.2. Dynamic Split Test. The prepared specimens were taken out from the environmental chamber; afterwards, the dynamic split test was conducted immediately. Since the test duration was extremely short, the temperature of the samples was regarded as unchanged. To understand the influence of the fissure angle on the mechanical properties of fractured sandstone, dynamic splitting tests at $0^{\circ}, 30^{\circ}, 60^{\circ}$, and $90^{\circ}$ were performed (Figure 2 ). The impact velocity was $2.2 \mathrm{~m} / \mathrm{s}$, and the crack growth process was recorded with high-speed photography equipment.

2.3. Split Hopkinson Pressure Bar. The SHPB test is based on two fundamental assumptions: one-dimensional stress wave in the elastic rod and the uniformity of stress in the specimen. During testing, the specimen is held between the incident and transmitted bar (Figure 2). A copper ring sheet is used to reshape the test stress waveform to eliminate the wave dispersion, and petroleum jelly is applied to reduce friction. The striker hits the incident bar at an initial speed, generates a stress wave in the incident bar, and propagates forward. After reaching the sample, a stress balance is achieved after multiple reflections. As the specimen deforms, it generates reflected and transmitted waves.

According to the one-dimensional elastic wave theory, the average applied load at both ends of the rod is 


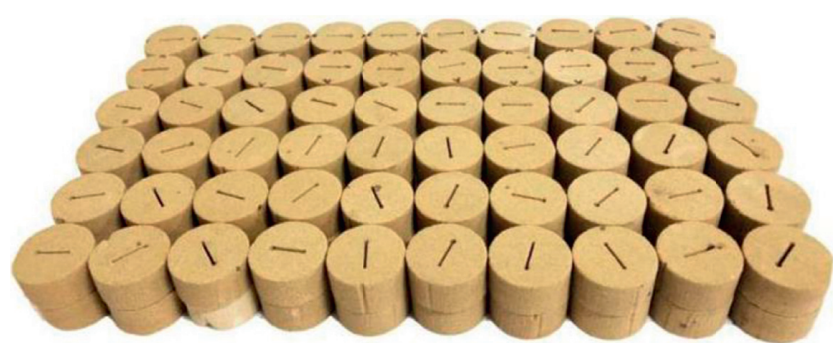

(a)



(b)

Figure 1: Fractured sandstone samples. (a) Sandstone specimens containing single fissure. (b) Sandstone specimens after freezing.

TABLE 1: Basic physical and mechanical parameters of the sandstone used.

\begin{tabular}{lccccc}
\hline Sample & Density $\left(\mathrm{g} / \mathrm{cm}^{3}\right)$ & Porosity $(\%)$ & P-wave velocity $(\mathrm{m} / \mathrm{s})$ & Uniaxial compressive strength $(\mathrm{MPa})$ & Poisson's ratio \\
\hline Saturation & $2152-2198$ & $19.56-20.12$ & $2650-2695$ & $19.65-20.18$ & $0.21-0.24$ \\
\hline
\end{tabular}



Figure 2: Diagram of the SHPB test system.

$$
P(t)=\frac{P_{1}+P_{2}}{2}=E_{s} A_{b} \frac{\varepsilon_{I}+\varepsilon_{R}+\varepsilon_{T}}{2}
$$

where $P_{1}$ and $P_{2}$ are the loads on both ends; $E_{s}$ is the elastic modulus of the sample; $A_{b}$ is the cross-sectional area of the pressure bar; and $\varepsilon_{I}, \varepsilon_{R}$, and $\varepsilon_{T}$ are the strain values of the incident wave, reflected wave, and transmitted wave as collected by the strain gauge.

The assumption of stress homogenization suggests that after the specimen reaches its internal stress balance, its stress distribution remains nearly the same as the stress distribution under static loads. Thus, the dynamic tensile stress at the center of the specimen is

$$
\sigma(t)=\frac{P_{1}(t)}{\pi R B}=\frac{E_{s} A_{b} \varepsilon_{T}(t)}{\pi R B},
$$

where $R$ and $B$ are the radius and height of the specimen, respectively.

\section{Results and Discussion}

3.1. Dynamic Equilibrium. In the dynamic split tests, the load conditions of the constant strain rate must be satisfied so that the internal force of the specimen is uniform. According to the work of Liang et al. [24] on wave-shaping materials in the SHPB test system, a copper sheet with holes is selected as the shaper. The voltage signal obtained during testing is shown in Figure 3(a), where the reshaped waveform is a sine wave. When the wave propagates in the specimen, after four transmissions and reflections, it is considered that the internal stress balance of the specimen is reached. The sample wave speed is $2670 \mathrm{~m} / \mathrm{s}$, and the specimen diameter is $5 \mathrm{~cm}$. Therefore, the specimen can attain the stress equilibrium state after $75 \mu \mathrm{s}$. It is seen from Figure 3(a) that the rising edge time is $85 \mu \mathrm{s}$, which can be considered as the specimen reaches a constant strain rate loading state. 


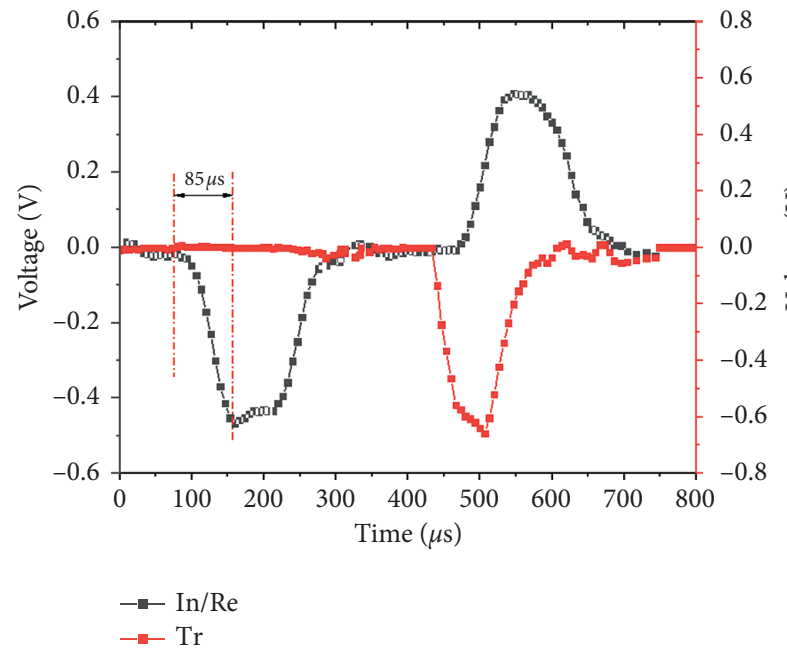

(a)

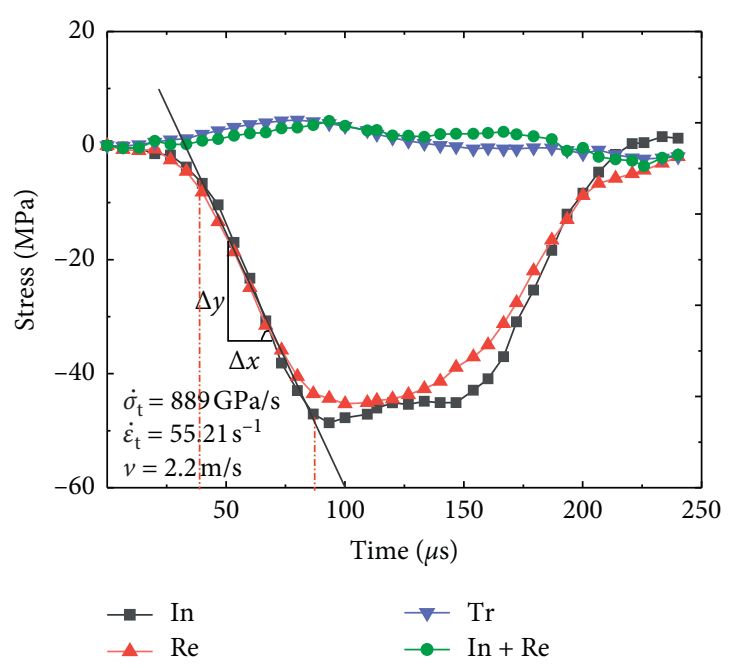

(b)

FIgURE 3: Evolution curves of the voltage (a) and stress (b) with time.

Figure 3(b) is the obtained stress time history curve. The rising edge of the incident stress and the reflected stress curve nearly overlapped, and the linear slope of the increasing incident stress can be considered as the loading rate. The impact speed is maintained equal during testing, which means that the same loading rate is applied to the specimen. However, the strain rate changes with variations in the temperature and loading angle. The incident stress wave+ reflected stress waves and the transmitted stress wave nearly coincide, indicating that the sample has reached the stress equilibrium condition and the test data are highly accurate. According to the experimental results, the presence of ice will affect the propagation of stress wave. Since the longitudinal wave velocity of the two is different, they will be reflected and transmitted at the interface, but the dynamic stress equilibrium will not be affected.

3.2. Stress-Strain Curve. The mechanical properties of the material, such as peak strength and elastic modulus, can be obtained from the characteristics of the stress-strain curves. Figure 4 shows the stress-strain curves obtained from the dynamic splitting tests of fractured sandstone under different freezing temperatures and loading angles.

It is seen that the curve can be divided roughly into three stages. The first stage is the elastic stage where the stress linearly increases with the strain and the sample absorbs energy. Thus, elastic energy storage is achieved, which is used for the next stage of crack propagation and coalescence. The slope of this stage can be used as the tensile modulus of the sample. The second stage is the plastic development stage where the growth rates of the stress with strain slowdown, which shows the characteristics of strain hardening. As the temperature decreases, the proportion of this stage in the stress curve gradually decreases, and the internal microcracks in the sample expand rapidly and reach their tensile stress limit after absorbing energy. The third stage is the failure stage, where the stress decreases with the strain. As the temperature decreases, the decline rate of the stress is enhanced, which may be caused by the shrinkage of the rock matrix and the enhancement of brittleness. This stage shows the obvious characteristics of plastic softening.

Under the same freezing temperature, the stress-strain curves of fractured sandstone with different fissure angles are different, mainly reflected in the slope of elastic stage and failure stage, and the length of the plastic stage, but none of them show a certain rule. With lower temperature, the slope of the elastic stage first decreases and then increases; the corresponding peak strain and the length of the plastic stage show a similar trend. This should be attributed to the coupling effects of frost damage-induced weakening and freezinginduced strengthening. As temperature decreases, pore water freezes and its volumetric expansion during freezing expands pores and microcracks; rock is thus damaged. On the other hand, ice in pores acts as both cement providing extra adhesive force and filling providing supporting force during rock failure; therefore, rock is strengthened.

3.3. Peak Stress. The peak stress is the ultimate bearing capacity of a material when it fails and is an important parameter to characterize rock strength. The maximum value on the stress-strain curve obtained from the dynamic splitting test of frozen sandstone is its tensile strength, and its change law is shown in Figure 5. It is seen that, under the test conditions, the dynamic tensile strength of the fractured sandstone varied with the loading angle within only $\pm 0.5 \mathrm{MPa}$ when at the same temperature, which does not form a specific change rule. As the temperature decreases, the strength of the fractured sandstone gradually increases. The change rules of the cracks at each dip are nearly the same, and a linear relationship is fit. This may be due to the small impact speed of the test and the small influence of the fissure angle on the strength of the specimen. The strength of the fissure ice and rock matrix is the primary controlling factor for the strength of the fractured sandstone. 


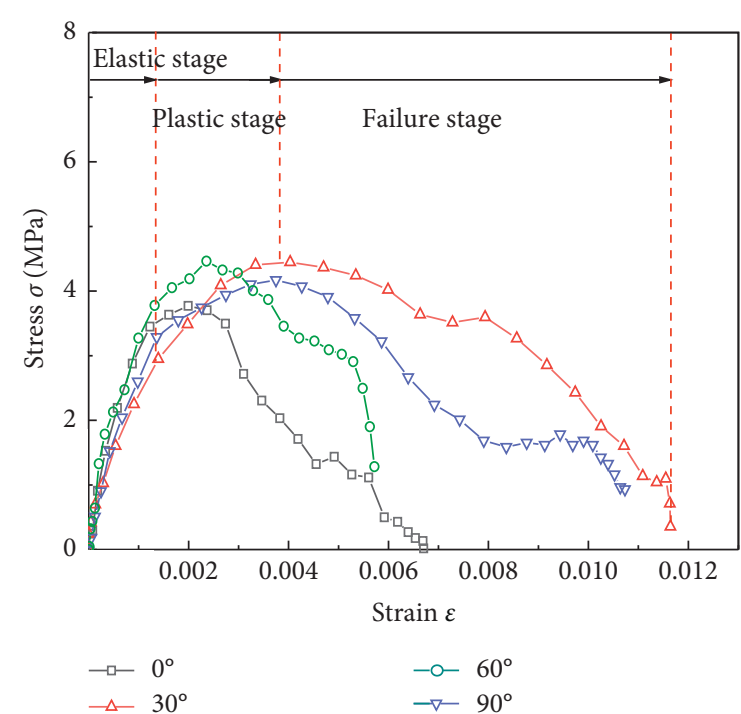

(a)

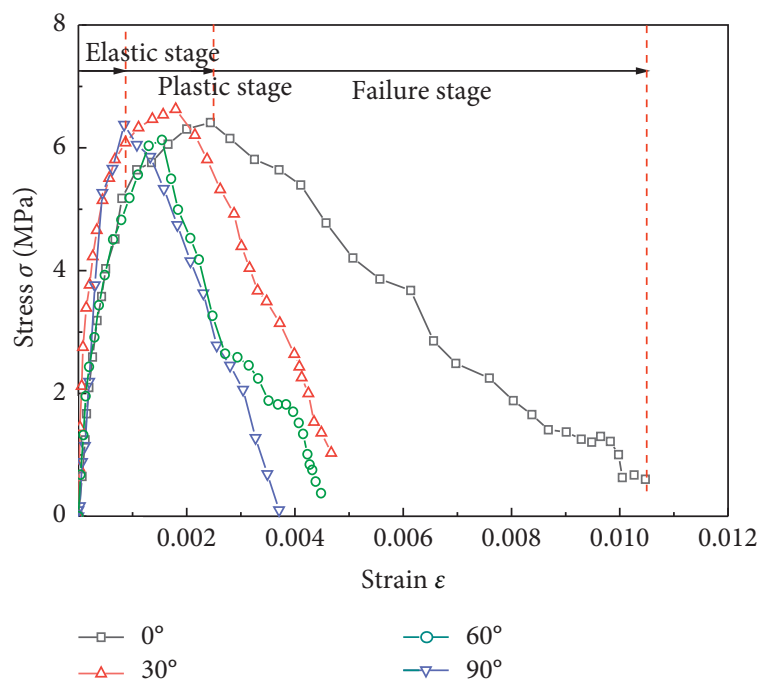

(c)

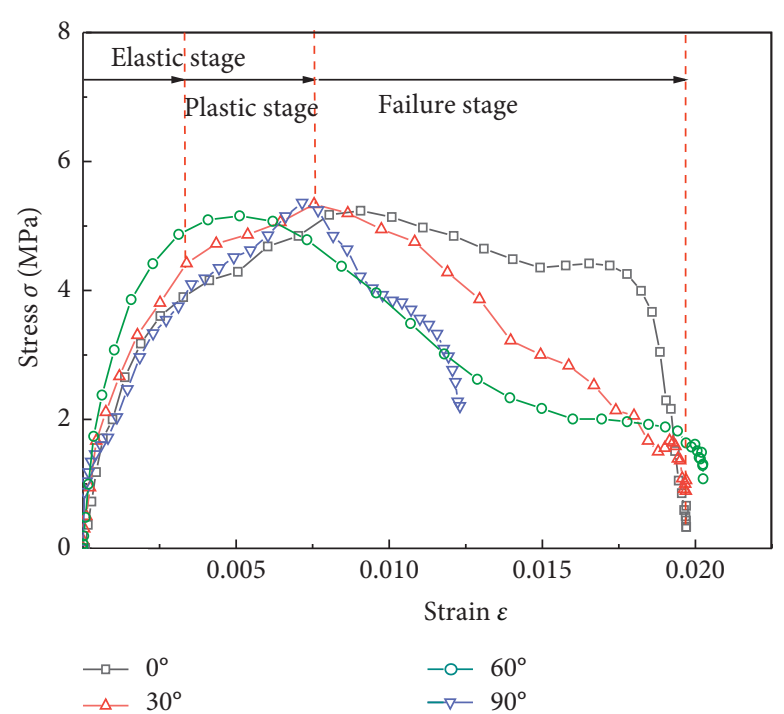

(b)



(d)

Figure 4: Dynamic splitting stress-strain curve of fractured sandstone at various fissure angles and subzero temperatures. (a)T $=-5^{\circ} \mathrm{C}$. (b) $\mathrm{T}=-10^{\circ} \mathrm{C}$. (c) $\mathrm{T}=-15^{\circ} \mathrm{C}$. (d) $\mathrm{T}=-20^{\circ} \mathrm{C}$.

3.4. Crack Propagation and Coalescence. According to the dynamic splitting test process of fractured sandstone at different freezing temperatures, the failure mode of the sample under the same fissure angle is basically the same and does not change significantly with lower temperatures. The failure process of the specimen collected at $-5^{\circ} \mathrm{C}$ is analyzed as an example. Photos of the failure process at each loading angle collected with high-speed photography are shown in Figures 6 and the schematic diagram of the failure process is shown in Figure 7.

It is seen from Figure 6 that the loading angle significantly impacts the dynamic split failure model of fractured sandstone. When the impact loading direction is parallel to the fissure $\left(\theta=0^{\circ}\right)$, tensile failure of the sample along the loading direction occurs when the fissure ice is detached from the fissure wall. The compression strength of the ice is much greater than the tensile strength at the interface, so the specimen is stretched along the normal direction of the artificial fissure. Moreover, there is a stress concentration at the contact end of the incident rod and the test piece. Under the continuous action of the stress wave, the rock matrix in this area is crushed into small lumps (Figures 6(a) and $7(\mathrm{a}))$.

When the loading direction is not parallel to the artificial fissure (not perpendicular as well), tensile crack is initiated at the tip of the artificial fissure before it propagates to the contact surface between the sample and the pressure bar. At small fissure angles (for instance, $\theta=30^{\circ}$ ), the ice-rock interface in the fissure breaks under tension which is the final stage of failure; that is, the sample only exhibits tensile cracking (Figures 6(b) and 7(b)). While at large fissure angles (e.g., $\theta=60^{\circ}$ ), the ice-rock interface in the fissure experiences shear failure before the final rupture of the sample (Figures 6(c) and 7(c)). 


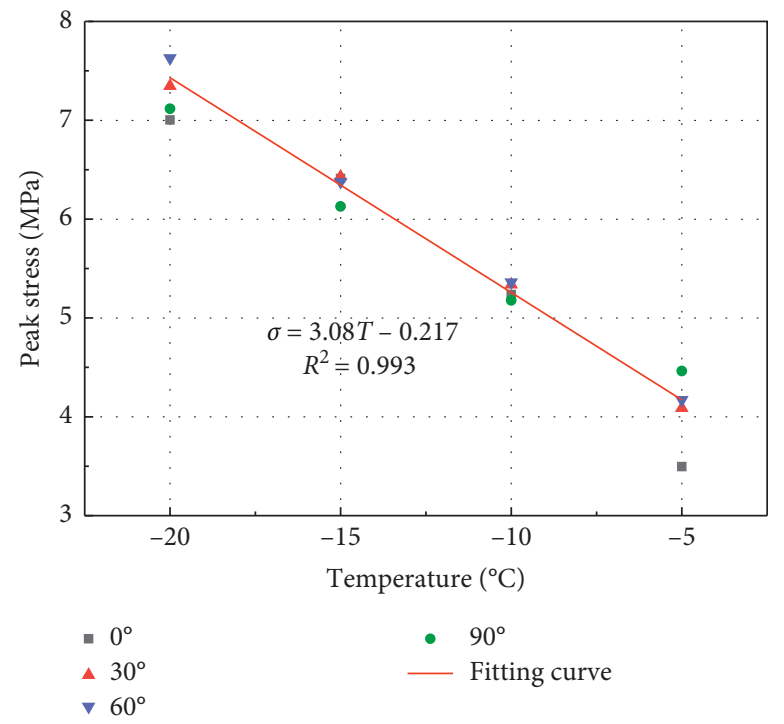

FIGURE 5: Peak stress change of frozen fractured sandstone with loading angle and freezing temperature.



$0 \mu \mathrm{s}$



$136 \mu \mathrm{s}$

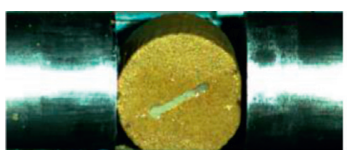

$0 \mu \mathrm{s}$

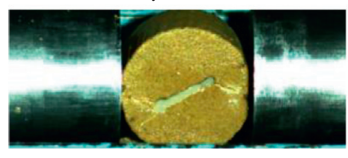

$124 \mu \mathrm{s}$

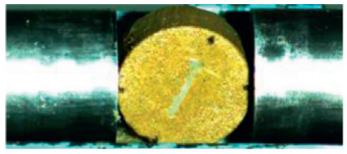

$0 \mu \mathrm{s}$

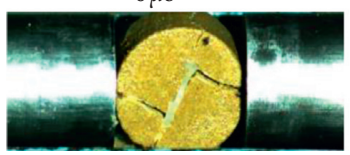

$138 \mu \mathrm{s}$

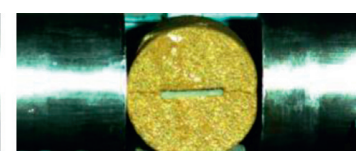

$34 \mu \mathrm{s}$

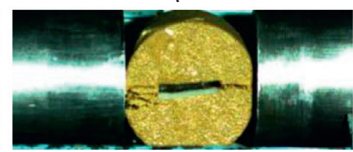

$155 \mu \mathrm{s}$

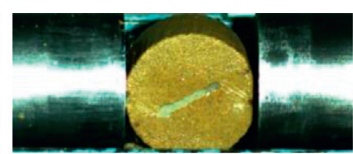

$45 \mu \mathrm{s}$

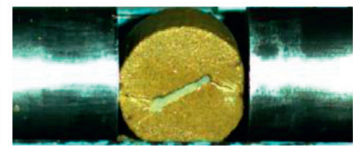

$144 \mu \mathrm{s}$

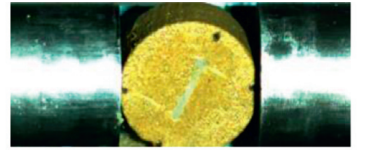

$35 \mu \mathrm{s}$

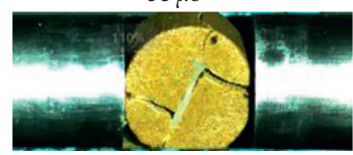

$183 \mu \mathrm{s}$

(a)

(b)

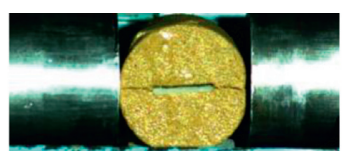

$65 \mu \mathrm{s}$



$216 \mu \mathrm{s}$

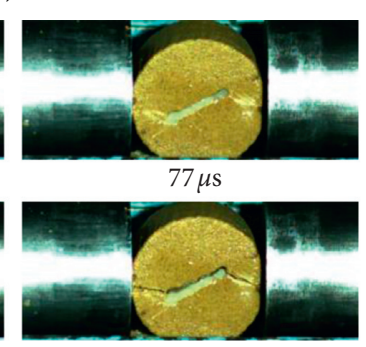

$188 \mu \mathrm{s}$

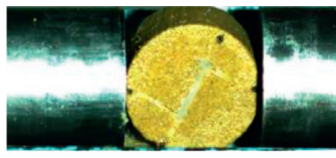

$70 \mu \mathrm{s}$



$224 \mu \mathrm{s}$

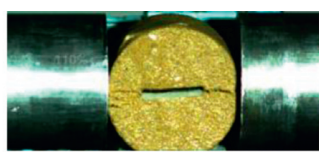

$121 \mu \mathrm{s}$

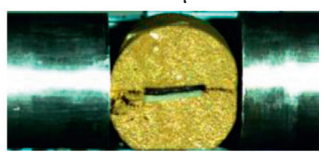

$257 \mu \mathrm{s}$

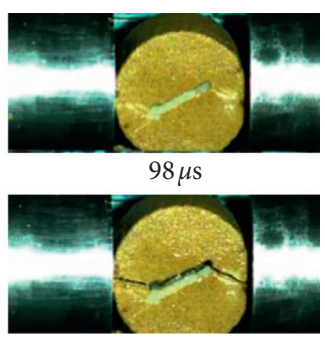

$218 \mu \mathrm{s}$



$102 \mu \mathrm{s}$

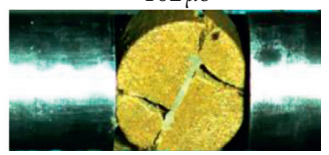

$279 \mu \mathrm{s}$

(c)

Figure 6: Continued. 


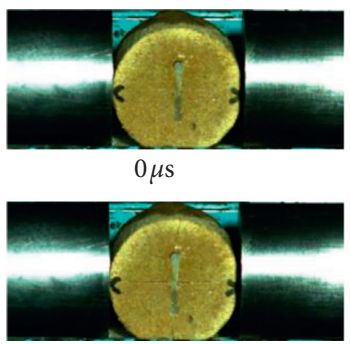

$130 \mu \mathrm{s}$

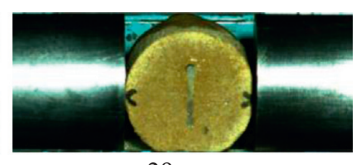

$28 \mu \mathrm{s}$

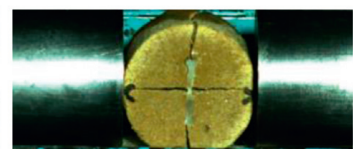

$188 \mu \mathrm{s}$
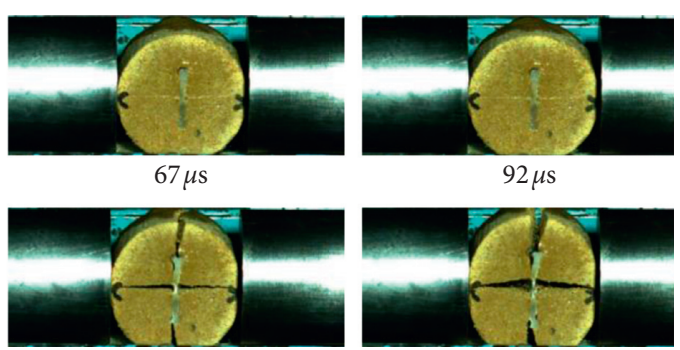

$235 \mu \mathrm{s}$

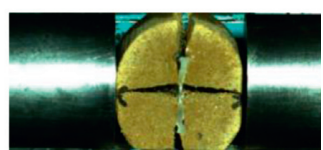

$274 \mu \mathrm{s}$

(d)

Figure 6: Failure process of samples with different fissure angles recorded by the high-speed photography at $-5^{\circ} \mathrm{C}$. (a) $T=-5^{\circ} \mathrm{C}, \theta=0^{\circ}$. (b) $T=-5^{\circ} \mathrm{C}, \theta=30^{\circ}$. (c) $T=-5^{\circ} \mathrm{C}, \theta=60^{\circ}$. (d) $T=-5^{\circ} \mathrm{C}, \theta=90^{\circ}$.


(a)
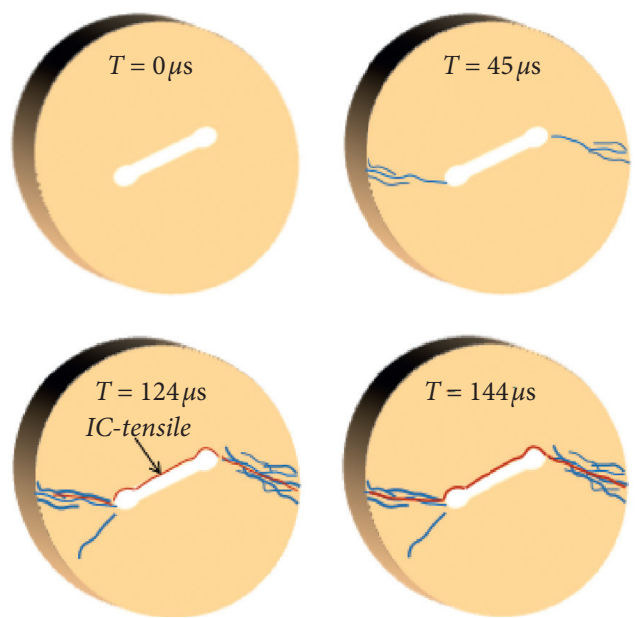
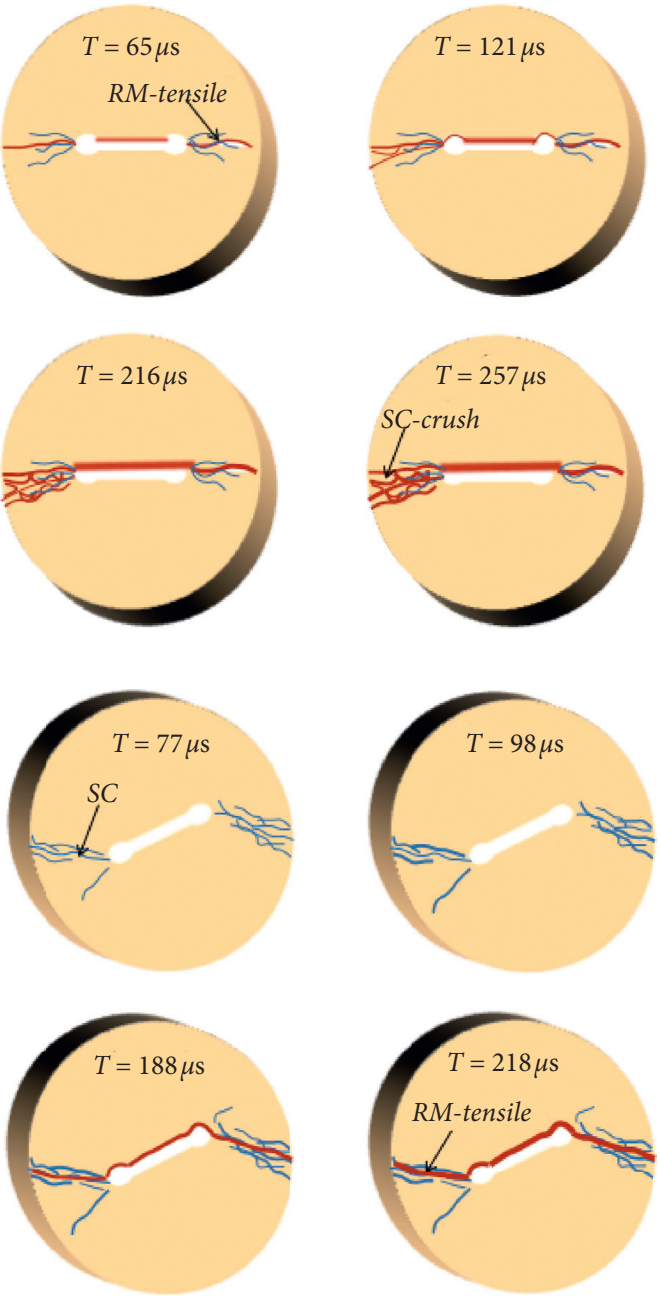

(b)

Figure 7: Continued. 

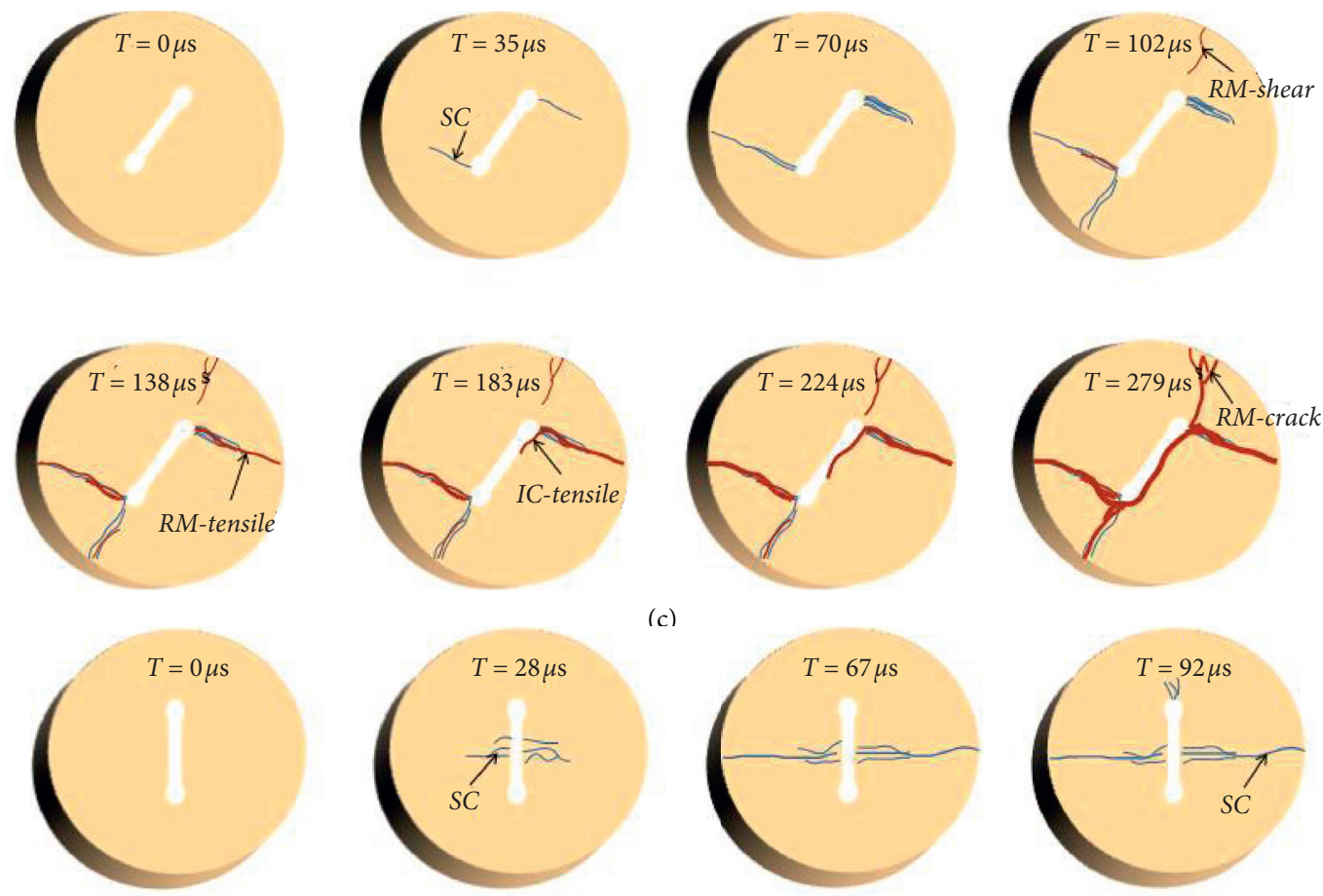

(c)
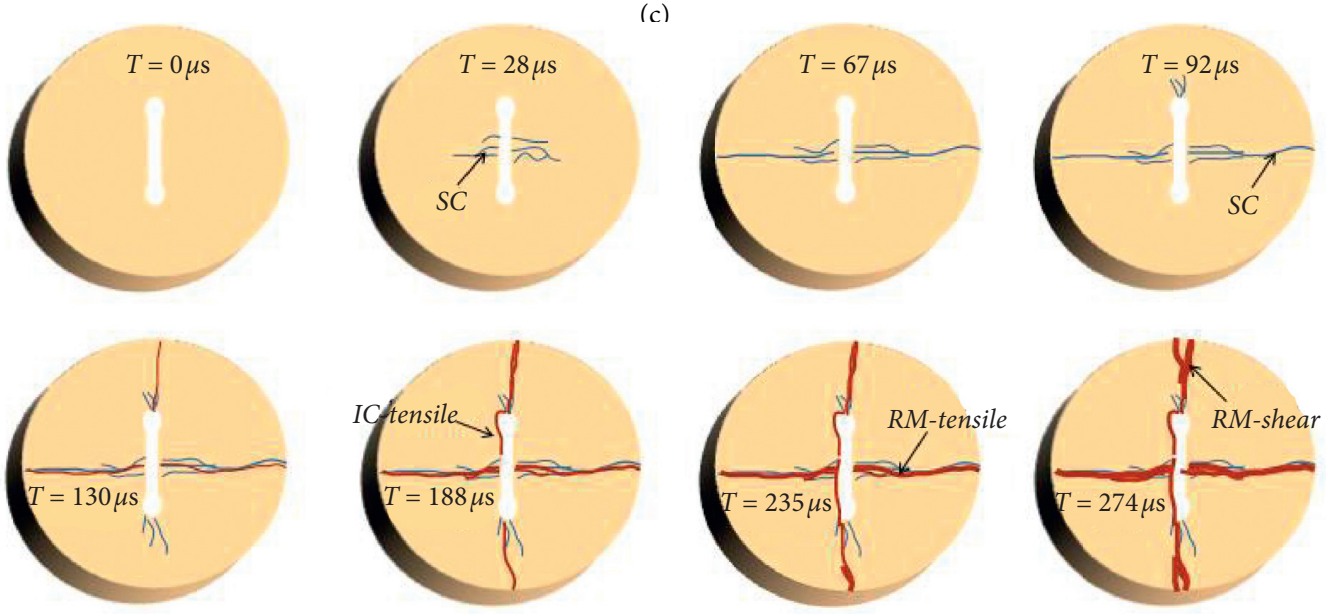

(d)

FIGURE 7: Schematic diagram of crack propagation in the fractured sandstone. (Note: IC is interface crack; RM is rock matrix; SC is stressconcentration) (a) $T=-5^{\circ} \mathrm{C}, \theta=0^{\circ}$. (b) $T=-5^{\circ} \mathrm{C}, \theta=30^{\circ}$. (c) $T=-5^{\circ} \mathrm{C}, \theta=60^{\circ}$. (d) $T=-5^{\circ} \mathrm{C}, \theta=90^{\circ}$.

In the case that the impact loading direction is perpendicular to the artificial fissure $\left(\theta=90^{\circ}\right)$, tensile crack is initiated at the center of the specimen along the loading direction. With the propagation of the tensile crack towards the pressure bar, fissure ice is pulled apart in the middle. Afterwards, tensile cracking occurs at the top and bottom edge of the sample along the artificial fissure direction, which is caused by stretching waves formed after the reflection of the stress wave (Figures 6(d) and 7(d)).

The above experimental results show that the failure modes of specimens differ under different loading angles; the underlying mechanisms are embedded in the interaction between fissure ice and rock matrix. Under an impact load, stress-concentration first appears at the ice-rock interface in the artificial fissure. Regardless of the fissure angle, tensile cracking is initiated at the stress-concentration zone and then propagates towards the loading end. Fissure ice provides both resistance to deformation and resistance to crack propagation. When the fissure angle is 0 , fissure ice is under tension, and due to its resistance to deformation, tensile cracking will not be initiated until the ice-rock interface is detached (Figure 8(a)). In the case of nonzero loading angles (not $90^{\circ}$ neither), tensile cracking is initiated close to the tip of the fissure and propagates towards the loading bar; afterwards, however, shear cracking dominates the failure process. The cohesion at the ice-rock interface provides resistance to shear cracking, after the shear failure of which final failure occurs (Figure 8(b)). When the impact loading direction is perpendicular to the artificial fissure $\left(\theta=90^{\circ}\right)$, tensile cracking is initiated at the center of the sample along the loading direction. With the propagation of the tensile crack towards the pressure bar, fissure ice is pulled apart in the middle, suggesting that tensile strength of ice itself provides the resistance to failure in this case.

\section{Constitutive Model}

4.1. Establishment of the Constitutive Relationship. Combining the statistic damage model and viscoelastic model, Shan [24] built a time effect damage model of rock under dynamic loading. Based on this model, we considered the influence of fissure angle and freezing temperature on rock constitutive relation and then built a dynamic constitutive model for frozen fractured sandstone. 


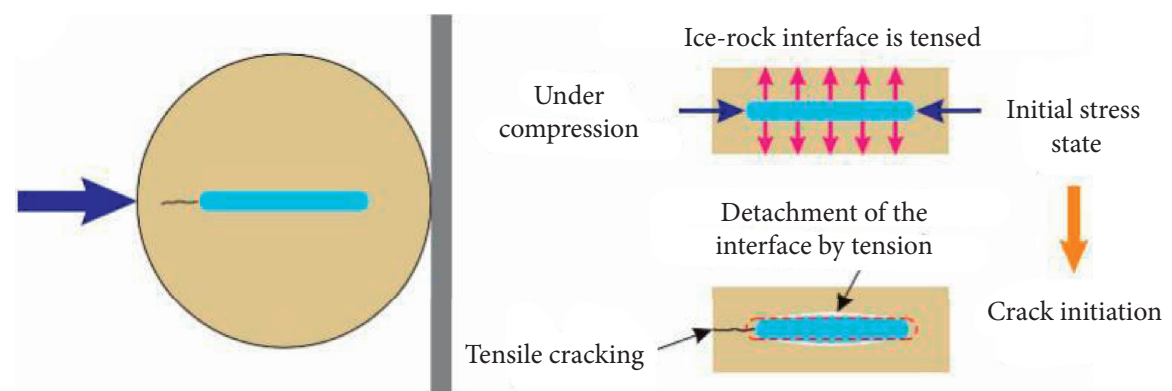

(a)


(b)

FIgURE 8: Schematic diagram of the mechanism of how ice alters the dynamic properties of frozen fractured sandstone.

The basic assumptions of this model are as follows:

(1) The interior microelements of rock are regarded as the parallel combination of damage element and viscous element, which satisfies

$$
\begin{gathered}
\varepsilon=\varepsilon_{a}=\varepsilon_{b}, \\
\sigma=\sigma_{a}+\sigma_{b},
\end{gathered}
$$

where $\varepsilon$ a is the strain of damage element; $\varepsilon_{b}$ is the strain of viscous element; $\sigma_{a}$ is the stress of damage element; and $\sigma_{b}$ is the stress of viscous element.

(2) Under the static load, the viscous element does not work. It only works when the loading rate reaches a certain value; its constitutive relation is

$$
\sigma=\eta \frac{\mathrm{d} \varepsilon}{\mathrm{d} t}
$$

where $\eta$ is the viscosity coefficient.

(3) Based on the heterogeneity and anisotropy of fractured rock mass, the physical properties of each element are in probability distribution. So, the mechanical properties of the element can be mathematically described by the statistical method. It is assumed that the strength of rock elements obeys Weibull distribution [25], and its probability density function is

$$
P(\varepsilon)=\frac{m}{\alpha}\left(\frac{\varepsilon}{\alpha}\right)^{m-1} \exp \left[-\left(\frac{\varepsilon}{\alpha}\right)^{m}\right]
$$

where $P(\varepsilon)$ is the corresponding intensity probability and $m$ and $\alpha_{0}$ are Weibull distribution constants.

In the process of deformation and failure of fractured rock mass under load, the axial stress is mainly borne by four parts: intact rock, the damage caused by fissure, the damage caused by load, and the damage under the coupling action of fissure and load. In the axial direction, it is assumed that the total element area of fractured rock mass is $A$, the damage element area caused by prefabricated fissure is $A_{\beta}$, the damage element area caused by the load is $A_{s}$, and the damage element area caused by coupling of fissure and load is $A_{1}$.

The damage caused by fissure $\left(D_{\beta}\right)$ can be defined as the ratio of the damage element area caused by the prefabricated fissure to the total element area:

$$
D_{\beta}=\frac{A_{\beta}}{A} .
$$

The fractured rock mass is further damaged under the action of load, and the damage variable under load is defined as $\left(D_{S}\right)$

$$
D_{s}=\frac{A_{s}-A_{1}}{A-A_{\beta}} .
$$

As a whole, the microelement failure of rock mass is caused by the combined action of prefabricated fissure and load. Therefore, the total damage variable of fractured rock mass under load can be defined according to the final damage degree of rock mass:

$$
D_{t}=\frac{A_{s}+A_{\beta}-A_{1}}{A} .
$$




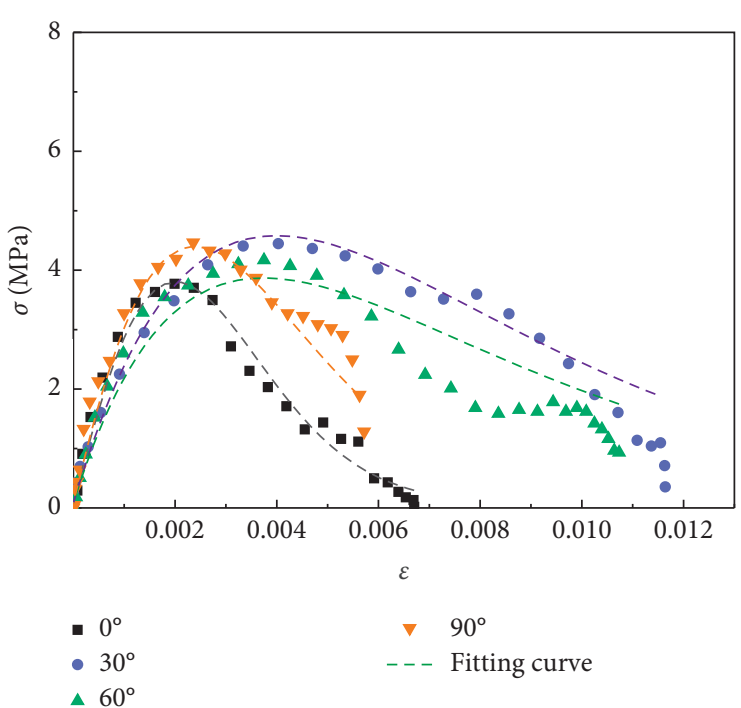

(a)

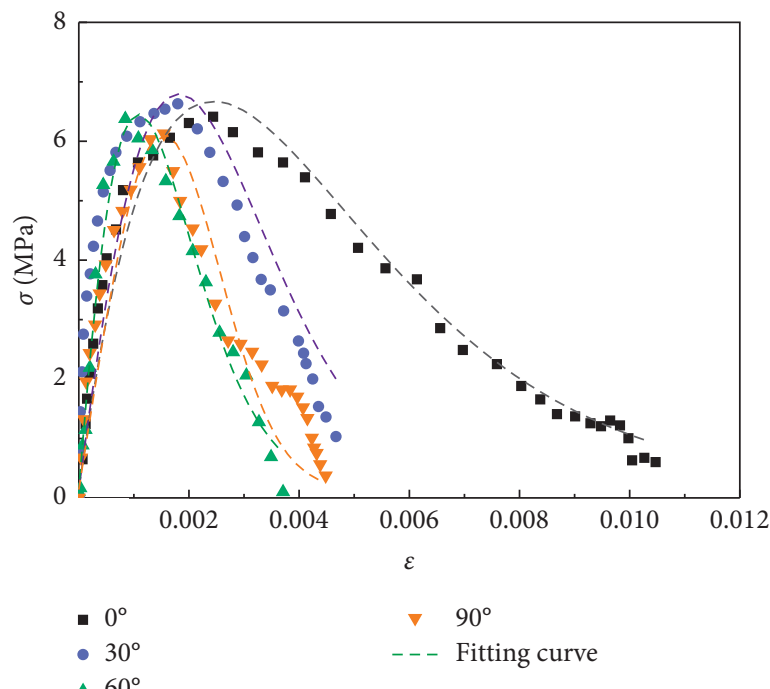

(c)

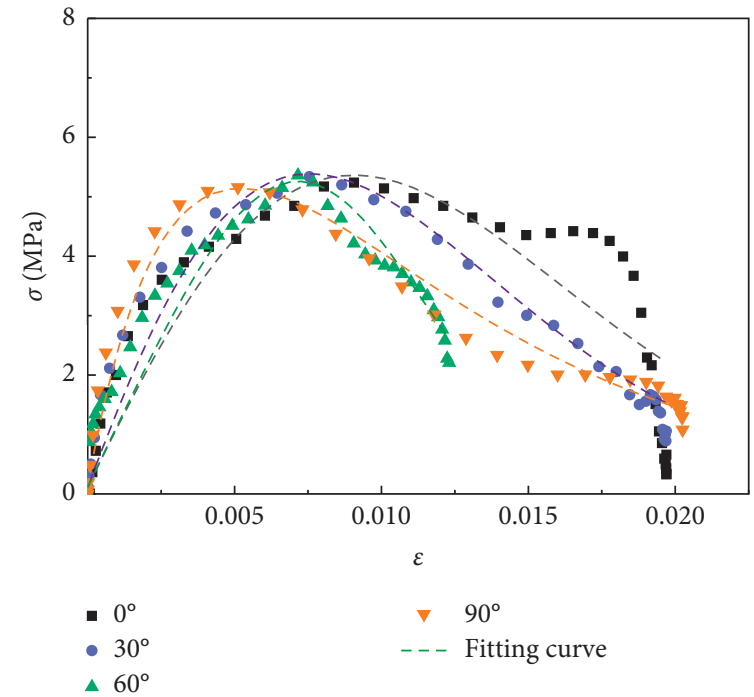

(b)

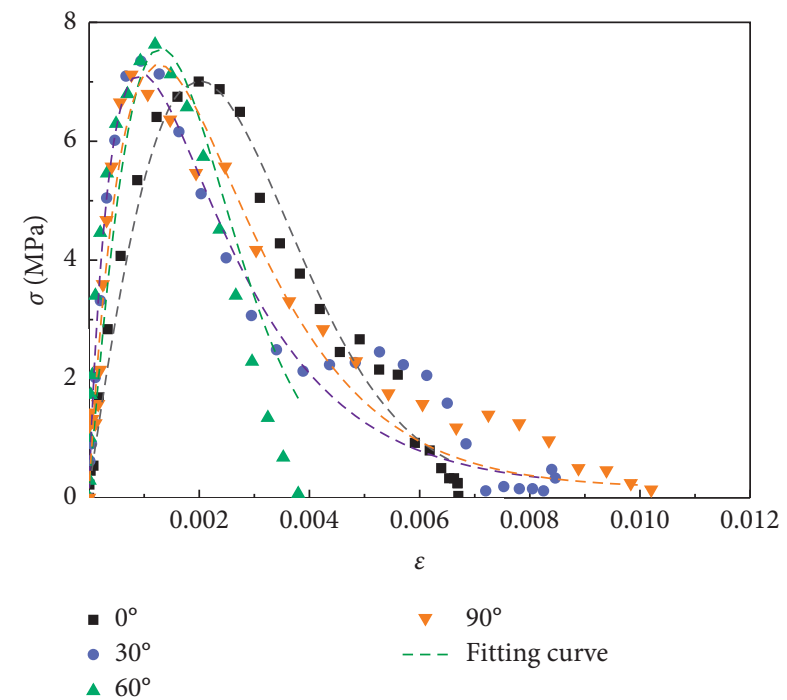

(d)

Figure 9: Fitting curve of the constitutive equation. (a) $T=-5^{\circ} \mathrm{C}$. (b) $T=-10^{\circ} \mathrm{C}$. (c) $\mathrm{T}=-15^{\circ} \mathrm{C}$. (d) $\cdot T=-20^{\circ} \mathrm{C}$.

Substituting equations (7) and (8) into (9), the relationship among $D_{\beta}, D_{S}$, and $D_{t}$ can be obtained:

$$
D_{t}=D_{s}+D_{\beta}-D_{s} D_{\beta}
$$

It can be seen from equation (10) that the combined action of fissure and load aggravates the total damage of rock, but the coupling action of the two weakens the total damage to some extent and shows obvious nonlinear characteristics.

According to the theory of macroscopic phenomenological damage mechanics, the degree of deterioration inside the material can be characterized by the response of macroscopic mechanical properties of the rock mass. Therefore, the elastic modulus was selected as the measurement benchmark of the initial damage of the fractured rock mass, and $D_{\beta}$ was defined as

$$
D_{\beta}=1-\frac{E_{\beta}}{E_{0}},
$$

where $\beta$ is the fissure angle and $E_{\beta}$ is the elastic modulus of fractured rock mass with different fissure angles. $E_{0}$ is the elastic modulus of intact rock.

The deformation and failure of rock mass are a continuous process of continuous internal damage of material. By integrating equation (6), the damage accumulation effect of the destruction of the element can be obtained, and the damage variable under load can be expressed as

$$
D_{s}=\int_{0}^{\varepsilon} P(\varepsilon) d \varepsilon=1-\exp \left[-\left(\frac{\varepsilon}{\alpha}\right)^{m}\right] .
$$

Substituting equations (11) and (12) into (10), the total damage of fractured rock mass can be obtained as follows: 


$$
D_{t}=1-\frac{E_{\beta}}{E_{0}} \exp \left[-\left(\frac{\varepsilon}{\alpha}\right)^{m}\right] .
$$

According to the Lemaitre strain equivalent hypothesis, the constitutive relation of fractured rock mass is

$$
[\sigma]=\left[\sigma^{*}\right]\left(1-D_{t}\right)=[E][\varepsilon][1-D],
$$

where $[\sigma]$ is the nominal stress matrix; $\left[\sigma^{*}\right]$ is the effective stress matrix; $D$ is the damage variable; $[E]$ is the elastic matrix; and $[\varepsilon]$ is the strain matrix.

According to (13) and (14), the constitutive relation of the damaged body under uniaxial condition can be written as

$$
\sigma_{a}=E_{0}\left(1-D_{t}\right) \varepsilon=E_{\beta} \varepsilon \exp \left[-\left(\frac{\varepsilon}{\alpha}\right)^{m}\right] .
$$

According to the geometrical conditions of the stressstrain curve, we get

$$
\begin{aligned}
a & =\frac{\varepsilon_{\max }}{(1 / m)^{1 / m}}, \\
m & =\frac{1}{\ln \left(E \varepsilon_{\max } / \sigma_{\max }\right)},
\end{aligned}
$$

where $\sigma_{\max }$ is the peak stress and $\varepsilon_{\max }$ is the strain at peak stress. Substituting equations (16) and (17) into equation (15) gives

$$
\sigma_{a}=E_{\beta} \varepsilon \exp \left[-\frac{1}{m}\left(\frac{\varepsilon}{\varepsilon_{\max }}\right)^{m}\right] .
$$

According to hypotheses (1) and (2), the dynamic damage constitutive relation of fractured rock mass under uniaxial condition can be obtained by combining equations (3)-(5) and (18):

$$
\sigma=\sigma_{a}+\sigma_{b}=E_{\beta} \varepsilon \exp \left[-\frac{1}{m}\left(\frac{\varepsilon}{\varepsilon_{\max }}\right)^{m}\right]+\eta \dot{\varepsilon} .
$$

Considering the influence of freezing temperature on dynamic constitutive properties of fractured sandstone, we add the temperature term to equation (19), so it becomes

$$
\sigma=\left\{E_{\beta} \varepsilon \exp \left[-\frac{1}{m}\left(\frac{\varepsilon}{\varepsilon_{\max }}\right)^{m}\right]+\eta \dot{\varepsilon}\right\} T^{* n},
$$

where $T^{* n}$ is the temperature influencing factor, which can be calculated by the following equation:

$$
T^{*}=\frac{T}{T_{n}},
$$

where $T$ is the freezing temperature of frozen fractured sandstone, $T_{n}$ is the reduced parameter of temperature, and the value of $T_{n}$ is $-5^{\circ} \mathrm{C}$.

So, the final dynamic constitutive model for frozen fractured sandstone is

$$
\sigma=\left\{E_{\beta} \varepsilon \exp \left[-\frac{1}{m}\left(\frac{\varepsilon}{\varepsilon_{\max }}\right)^{m}\right]+\eta \dot{\varepsilon}\right\}\left(\frac{T}{T_{n}}\right)^{n} .
$$

TABLE 2: Constitutive parameters.

\begin{tabular}{lccccc}
\hline Sample number & $E_{\beta}(\mathrm{GPa})$ & $\varepsilon_{\max }(\%)$ & $m$ & $\eta\left(10^{-3}\right)$ & $n$ \\
\hline$-5^{\circ} \mathrm{C} / 0^{\circ}$ & 3.307 & 0.201 & 1.7 & & \\
$-5^{\circ} \mathrm{C} / 30^{\circ}$ & 2.852 & 0.400 & 1.1 & & \\
$-5^{\circ} \mathrm{C} / 60^{\circ}$ & 2.742 & 0.374 & 1.0 & & \\
$-5^{\circ} \mathrm{C} / 90^{\circ}$ & 3.541 & 0.239 & 1.5 & 1.52 & 0.5 \\
$-10^{\circ} \mathrm{C} / 0^{\circ}$ & 0.713 & 0.906 & 1.8 & & \\
$-10^{\circ} \mathrm{C} / 30^{\circ}$ & 0.922 & 0.755 & 1.6 & & \\
$-10^{\circ} \mathrm{C} / 60^{\circ}$ & 0.726 & 0.716 & 2.8 & & \\
$-10^{\circ} \mathrm{C} / 90^{\circ}$ & 2.022 & 0.521 & 0.9 & & \\
\hline$-15^{\circ} \mathrm{C} / 0^{\circ}$ & 3.853 & 0.244 & 1.1 & & \\
$-15^{\circ} \mathrm{C} / 30^{\circ}$ & 3.968 & 0.181 & 1.6 & & \\
$-15^{\circ} \mathrm{C} / 60^{\circ}$ & 6.551 & 0.108 & 1.5 & & \\
$-15^{\circ} \mathrm{C} / 90^{\circ}$ & 3.396 & 0.154 & 2.4 & 1.52 & 0.5 \\
$-20^{\circ} \mathrm{C} / 0^{\circ}$ & 3.105 & 0.199 & 1.7 & & \\
$-20^{\circ} \mathrm{C} / 30^{\circ}$ & 12.95 & 0.094 & 0.8 & & \\
$-20^{\circ} \mathrm{C} / 60^{\circ}$ & 5.553 & 0.130 & 1.5 & & \\
$-20^{\circ} \mathrm{C} / 90^{\circ}$ & 7.689 & 0.076 & 1.0 & & \\
\hline
\end{tabular}

4.2. Parameter Determination. In equation (22), there are 5 parameters unknown. $\varepsilon_{\max }$ can be obtained directly from Figure 4 . The other 4 parameters can be obtained by fitting with the experimental curves. The fitting results are shown in Figure 9. All the parameters of the dynamic constitutive model of frozen fractured sandstone are listed in Table 2.

It can be seen from Figure 9 that the experimental data agree well with the constitutive equation fitting curves, which can accurately reflect the stress-strain relationship at each stage. This indicates that the dynamic tensile mechanical properties of frozen fractured sandstone can be characterized by the above dynamic constitutive relationship considering the effect of fissure angle and freezing temperature.

\section{Conclusions}

This study investigates the dynamic properties of frozen fractured sandstone. By adopting specimens containing a single fissure filled with ice, we reveal the first-order rules of how predominant factors (e.g., fissure angle and freezing temperature) affect the dynamic properties of frozen fractured rock. Accordingly, a constitutive model considering the effect of fissure angle and freezing temperature is proposed. We draw the following conclusions:

(1) In the dynamic splitting tests, the stress curves of the fractured sandstone are divided into three stages: elastic, plastic, and failure. Under different fissure angles, the dynamic tensile strength of the fractured sandstone has no obvious change rule at the same freezing temperature. As the temperature decreases, the dynamic tensile strength of fractured sandstone gradually increases following a linear relationship. With lower temperature, the slope of the elastic stage first decreases and then increases, and the corresponding peak strain and the length of the plastic stage show a similar trend. This should be attributed to the coupled effects of frost damage-induced weakening and freezing-induced strengthening. 
(2) The fissure angle significantly impacts the dynamic split failure model of fractured sandstone. When the impact loading direction is parallel to the fracture, tensile failure of the specimen along the loading direction occurs when the fissure ice is detached from the fissure wall. When the loading direction is not parallel to the artificial fissure (not perpendicular as well), tensile crack is initiated at the tip of the artificial fissure before it propagates to the contact surface between the specimen and the pressure bar. In the case that the impact loading direction is perpendicular to the artificial fissure, tensile crack is initiated at the center of the sample along the loading direction. With the propagation of the tensile crack towards the pressure bar, fissure ice is pulled apart in the middle. Afterwards, tensile cracking occurs at the top and bottom edge of the sample along the artificial fissure direction.

(3) The failure modes of specimens differ under different fissure angles; the underlying mechanisms are embedded in the interaction between fissure ice and rock matrix. Fissure ice provides both resistance to deformation and resistance to crack propagation. When the fissure angle is zero, fissure ice is under tension and, due to its resistance to deformation, tensile cracking will not be initiated until the ice-rock interface is detached. In the case of nonzero fissure angles (not 90 neither), shear cracking dominates the failure process after the initiation of tensile cracking. The cohesion at the ice-rock interface provides resistance to shear cracking. When the fissure angle is $90^{\circ}$, with the propagation of the tensile crack towards the pressure bar, fissure ice is pulled apart in the middle, suggesting that the tensile strength of ice itself provides resistance to failure in this case.

(4) Considering the effect of fissure angle and freezing temperature on dynamic mechanical properties of frozen fractured sandstone, a constitutive model describing the dynamic behavior of frozen fractured rocks is proposed employing the strain equivalence principle and time effect damage model. The test data agrees well with the constitutive equation curves, which can accurately reflect the stress-strain relationship at each stage.

\section{Data Availability}

The data used to support the findings of this study are included within the article.

\section{Conflicts of Interest}

The authors declared that there are no conflicts of interest.

\section{Acknowledgments}

The study was funded by the National Natural Science Foundation of China (Grant nos. 41702334 and 41702339) and the Key Research and Development Program in Shaanxi Province (2019SF-264).

\section{References}

[1] H. Jia, F. Zi, G. Yang et al., "Influence of pore water (ice) content on the strength and deformability of frozen argillaceous siltstone," Rock Mechanics and Rock Engineering, vol. 53, no. 2, pp. 967-974, 2020.

[2] S. Huang, Y. Ye, X. Cui, A. Cheng, and G. Liu, "Theoretical and experimental study of the frost heaving characteristics of the saturated sandstone under low temperature," Cold Regions Science and Technology, vol. 174, Article ID 103036, 2020.

[3] Y. Shen, H. Yang, J. Xi et al., "A novel shearing fracture morphology method to assess the influence of freeze-thaw actions on concrete-granite interface," Cold Regions Science and Technology, vol. 169, 2020.

[4] H. Zhang, C. Yuan, G. Yang et al., "A novel constitutive modelling approach measured under simulated freeze-thaw cycles for the rock failure," Engineering with Computers, vol. 37, no. 1, pp. 779-792, 2019.

[5] H. Jia, S. Ding, Y. Wang et al., "An NMR-based investigation of pore water freezing process in sandstone," Cold Regions Science and Technology, vol. 168, Article ID 102893, 2019.

[6] L. Tang, Y. Du, L. Liu, L. Jin, L. Yang, and G. Li, “ mechanism of unfrozen water on the frozen soil-structure interface during the freezing-thawing process," Geomechanics and Engineering, vol. 22, no. 3, pp. 245-254, 2020.

[7] Q. Sun, Z. Dong, and H. Jia, "Decay of sandstone subjected to a combined action of repeated freezing-thawing and salt crystallization," Bulletin of Engineering Geology and the Environment, vol. 78, no. 8, pp. 5951-5964, 2019.

[8] L. N. Y. Wong and H.-Q. Li, "Numerical study on coalescence of two pre-existing coplanar flaws in rock," International Journal of Solids and Structures, vol. 50, no. 22-23, pp. 3685-3706, 2013.

[9] R. Yang, S. Fang, W. Li, Y. Yang, and Z. Yue, "Experimental study on the dynamic properties of three types of rock at negative temperature," Geotechnical and Geological Engineering, vol. 37, no. 1, pp. 455-464, 2019.

[10] L. Weng, Z. Wu, and Q. Liu, "Dynamic mechanical properties of dry and water-saturated siltstones under sub-zero temperatures," Rock Mechanics and Rock Engineering, vol. 53, pp. 4381-4401, 2020.

[11] A. Mardoukhi, Y. Mardoukhi, M. Hokka, and V. T. Kuokkala, "Effects of test temperature and low temperature thermal cycling on the dynamic tensile strength of granitic rocks," Rock Mechanics and Rock Engineering, vol. 21, pp. 1-12, 2020.

[12] S. Nemat-Nasser and H. Horii, "Compression-induced nonplanar crack extension with application to splitting, exfoliation, and rockburst," Journal of Geophysical Research: Solid Earth, vol. 87, no. 8, pp. 6805-6821, 1982.

[13] F. Dai, S. Huang, K. Xia, and Z. Tan, "Some fundamental issues in dynamic compression and tension tests of rocks using split hopkinson pressure bar," Rock Mechanics and Rock Engineering, vol. 43, no. 6, pp. 657-666, 2010.

[14] T. De Kock, M. A. Boone, T. De Schryver et al., “A pore-scale study of fracture dynamics in rock using X-ray micro-CT under ambient freeze-thaw cycling," Environmental Science \& Technology, vol. 49, no. 5, pp. 2867-2874, 2015.

[15] P. Dong, B. Wu, K. Xia, and Q. Wang, "Fracture modes of single-flawed rock-like material plates subjected to dynamic compression," International Journal of Geomechanics, vol. 20, no. 9, Article ID 04020145, 2020. 
[16] X. Li, T. Zhou, and D. Li, "Dynamic strength and fracturing behavior of single-flawed prismatic marble Specimens under impact loading with a split-Hopkinson pressure bar," Rock Mechanics and Rock Engineering, vol. 50, no. 1, pp. 29-44, 2017.

[17] Z. Yan, F. Dai, Y. Liu, and H. Du, "Experimental investigations of the dynamic mechanical properties and fracturing behavior of cracked rocks under dynamic loading," Bulletin of Engineering Geology and the Environment, vol. 79, no. 10, pp. 5535-5552, 2020.

[18] Y. Li, F. Dai, M. Wei, and H. Du, "Numerical investigation on dynamic fracture behavior of cracked rocks under mixed mode I/II loading," Engineering Fracture Mechanics, vol. 235, Article ID 107176, 2020.

[19] Y. Yang, J. Wang, S. Fang, and N. Zhang, "Experimental study on dynamic mechanical properties of red sandstone under low temperatures," Journal of China Coal Society, vol. 43, no. 4, pp. 967-975, 2018.

[20] L. Wang, H. Su, Y. Qin, and S. Chen, "Study on dynamic constitutive model of weakly consolidated soft rock in western China," Shock and Vibration, vol. 2020, Article ID 8865013, 10 pages, 2020.

[21] L. Wang, H. Su, S. Chen, and Y. Qin, "Nonlinear dynamic constitutive model of frozen sandstone based on Weibull distribution," Advances in Civil Engineering, vol. 2020, Article ID 6439207, 12 pages, 2020.

[22] L. Weng, Z. Wu, Q. Liu, and Z. Wang, "Energy dissipation and dynamic fragmentation of dry and water-saturated siltstones under sub-zero temperatures," Engineering Fracture Mechanics, vol. 220, Article ID 106659, 2020.

[23] R. Shan, Y. Song, L. Song, and Y. Bai, "Dynamic property tests of frozen red sandstone using a split hopkinson pressure bar," Earthquake Engineering and Engineering Vibration, vol. 18, no. 3, pp. 511-519, 2019.

[24] S. Liang, "The study on damage evolution and constitutive model of the granite under constant strain rate impact", Ph.D dissertation, China University of Mining and Technology, Beijing, China, 2016.

[25] C. Fan, S. Li, D. Elsworth, J. Han, and Z. Yang, "Experimental investigation on dynamic strength and energy dissipation characteristics of gas outburst prone coal," Energy Science and Engineering, vol. 8, no. 4, pp. 1015-1028, 2020. 